Journal of Computer Science 3 (1): 51-56, 2007

ISSN 1549-3636

(c) 2007 Science Publications

\title{
Free Vibration Analysis of a Cross-Ply Laminated Composite Beam on Pasternak Foundation
}

\author{
${ }^{1}$ R.A. Jafari-Talookolaei and ${ }^{2}$ M.T.Ahmadian \\ ${ }^{1,2}$ Center of Excellence in Design, Robotics and Automation, School of Mechanical Engineering, Sharif \\ University of Technology, Azadi Ave., Tehran 11365, Iran
}

\begin{abstract}
In this study, free vibration analysis of a cross-ply laminated composite beam (LCB) on Pasternak foundation was investigated. Natural frequencies of beam on Pasternak foundation are computed using finite element method (FEM) on the basis of Timoshenko beam theory. Effect of both shear deformation and rotary inertia are implemented in the modeling of stiffness and mass matrices. The model was designed in such a way that it can be used for single-stepped cross-section, stepped foundation and multi-span beams. Results of few examples are compared with finding in literature and good agreements were achieved. Natural frequencies of LCBs with different layers arrangements (symmetric and non-symmetric) are compared. For multi-span beam, variation of frequency with respect to number of spans was also studied.
\end{abstract}

Key words: Free vibration, pasternak foundation, finite element, stepped cross-section beam, multispan beam

\section{INTRODUCTION}

Composite materials have numerous applications in aircraft and car industries because of the high strength to weight ratio, resistance in fatigue and low damping factor. Finding free vibration characteristics of LCBs is one of the bases for designing and modeling of industrial products. Beam analysis plays an important role in mechanical and civil structural design such as railway, car suspension system and structural foundation. Several researchers have investigated the free vibration of uniform cross-section LCBs with no foundation.

Patel et $a l .{ }^{[1]}$ have investigated Non-linear free flexural vibration/post buckling analysis of laminated orthotropic beams/columns on a two parameter elastic foundation (Pasternak). They have used Von-Karman strain-displacement relations and formulation consisted effects of shear deformation and rotary inertia. Thambiratnam and $\mathrm{Zhug}^{[2]}$ have implemented finite element method to study the free vibration analysis of isotropic beams with uniform cross section on an elastic foundation using Euler-Bernoulli beam theory. Banerjee ${ }^{[3]}$ has investigated the free vibration of axially laminated composite Timoshenko beams using dynamic stiffness matrix method. Yuan and Miller ${ }^{[4]}$ have studied static analysis of LCBs by uniform cross section using finite element method, respectively. Krishnaswamy et al. ${ }^{[5]}$ have studied the free vibration of LCBs including the effects of transverse shear and rotary inertia. Analytical solutions are obtained by the method of Lagrange multipliers. Chandrashekhara et $a l .{ }^{[6]}$ have presented exact solutions for the vibration of symmetrically LCBs. First-order shear deformation and rotary inertia has been included but Poisson effect has been neglected. Subramanian ${ }^{[7]}$ has investigated free vibration analysis of LCBs by using two higher order displacement based on shear deformation theories and finite elements. Both theories assume a quintic and quartic variation of in-plane and transverse displacements in the thickness coordinates of the beam respectively. Results indicate application of these theories and finite element model results in natural frequencies with higher accuracy.

In this study, applying the element given by Yuan $^{[4]}$, free vibration analysis of the LCB on Pasternak foundation is analyzed. The model is designed in such a way that it can be used for single-stepped cross-section. For the first time to-date, the same analysis was conducted for a single-stepped LCB on Paternak foundation. Stiffness and mass matrices of a cross-ply LCB on Pasternak foundation using the energy method are computed.

Uniform beam modeling: In this model, a LCB on Pasternak foundation with uniform cross-section is modeled. Every lamina has its on rotational degrees of freedom (DOFs) while additional DOFs for deflection are considered to be the same as reference layer(the lowest layer in the beam) and axial displacement are calculated based on the reference layer and compatibility relationships. In this analysis, effects of shear deformation and rotary inertia are considered (Timoshenko beam theory).
Corresponding Author:

R.A. Jafari-Talookolaei, Center of Excellence in Design, Robotics and Automation, School of Mechanical Engineering, Sharif University of Technology, Azadi Ave., Tehran 11365, Iran 
Modeling of single lamina beam element: Figure 1 represents a model of single lamina beam element. Geometrical variables considered to be $\mathrm{v}, \mathrm{u}$ and $\phi$ as vertical, axial and rotational displacements.

Using the following shape functions in the form of polynomials:

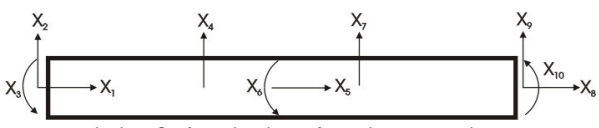

Fig. 1: Model of single lamina beam element

$u=\left\lfloor\begin{array}{lll}1 & x & x^{2}\end{array}\right\rfloor\left\{\begin{array}{l}a_{1} \\ a_{2} \\ a_{3}\end{array}\right\}=P_{u} a_{u}$

$v=\left[\begin{array}{llll}1 & x & x^{2} & x^{3}\end{array}\right]\left\{\begin{array}{l}a_{4} \\ a_{5} \\ a_{6} \\ a_{7}\end{array}\right\}=P_{v} a_{v}$

$\phi=\left[\begin{array}{lll}1 & x & x^{2}\end{array}\right]\left\{\begin{array}{l}a_{8} \\ a_{9} \\ a_{10}\end{array}\right\}=P_{\phi} a_{\phi}$

Where a's are polynomial coefficients. Variation of axial displacement at each cross-section is assumed to be a linear function of the distance to the centerline.

Considering shear strain as a linear function of both $\phi$ and $\mathrm{dv} / \mathrm{dx}$, therefore number of degree of polynomial for $\mathrm{v}$ is one order larger than that used for $\mathrm{u}$ and $\phi$. Finite element model for each beam element consists of five nodes: one at each end, one in the middle and two at one-third of length element from both ends as shown in Fig. 1. Numbers of DOFs for this element are vertical displacement $\mathrm{v}$ at all nodes but at the middle, axial displacement $\mathrm{u}$ and rotational displacement $\phi$ both at end points and midpoint, total of 10 DOFs. Shape functions are considered to be as following:

$$
\begin{aligned}
& \left\{\begin{array}{l}
u=N_{1} X_{1}+N_{2} X_{5}+N_{3} X_{8} \\
v=N_{4} X_{2}+N_{5} X_{4}+N_{6} X_{7}+N_{7} X_{9} \\
\phi=N_{1} X_{3}+N_{2} X_{6}+N_{3} X_{10}
\end{array}\right\} \\
& N_{1}=1+2 \xi^{2}-3 \xi, N_{2}=4 \xi-4 \xi^{2}, \\
& N_{3}=2 \xi^{2}-\xi, N_{4}=1-11 / 2 \xi+9 \xi^{2}-9 / 2 \xi^{3}, \\
& N_{5}=9 \xi-45 / 2 \xi^{2}+27 / 2 \xi^{3}, \\
& N_{6}=-9 / 2 \xi+18 \xi^{2}-27 / 2 \xi^{3}, \\
& N_{7}=\xi-9 / 2 \xi^{2}+9 / 2 \xi^{3}
\end{aligned}
$$

Where shape functions are obtained from Lagrange interpolation with variable $\xi$ equal to $\mathrm{x} / \mathrm{L}$. Loaddisplacement relations may be written as:

$\mathrm{P}=\mathrm{EAu} \mathrm{u}^{\prime}, \mathrm{F}=\mathrm{GA}\left(\mathrm{v}^{\prime}-\phi\right), \mathrm{M}$

$=E I \phi^{\prime}, P_{f}(x)=k_{\mathrm{f}} v-k v^{\prime \prime}$

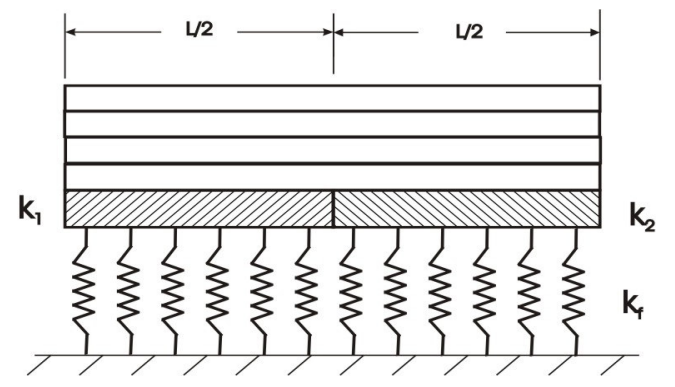

Fig. 2: Modeling of Pasternak foundation

Where $\mathrm{P}, \mathrm{F}, \mathrm{M}, \mathrm{P}_{\mathrm{f}}$ are axial force, shear force, bending moment and Pasternak foundation force per unit length, respectively. $\mathrm{k}_{\mathrm{f}}, \mathrm{k}$ are elastic and shear layer stiffness ,respectively. When $\mathrm{k}$ is equal to zero, foundation model would be the same as Winkler model. In the present study, shear layer stiffness $(\mathrm{k})$ is assumed to be $\mathrm{k}_{1}, \mathrm{k}_{2}$ in the two halves on which the beam is restring (Fig. 2). Primes denote derivatives with respect to $\mathrm{x}$. The symbols E, G, A and I represent Young's modulus, shear modulus, cross-section area and second moment of area, respectively.

Applying energy method for deriving stiffness matrix ${ }^{[8]}$, we obtain:

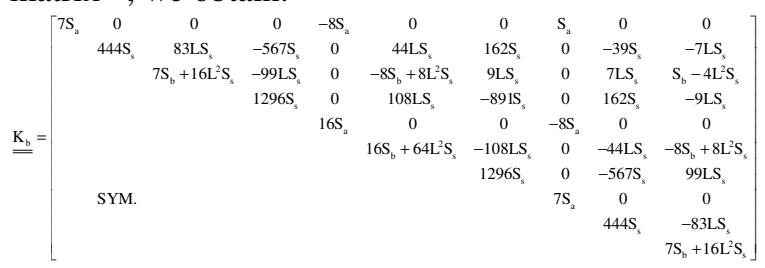

Stiffness matrix for Pasternak foundation can be found.

$$
\begin{aligned}
& \mathrm{U}_{\mathrm{F}}=\frac{1}{2} \int_{0}^{\mathrm{L}} \mathrm{k}_{\mathrm{f}} \mathrm{v}^{2} \mathrm{dx}+\frac{1}{2} \int_{0}^{\frac{\mathrm{L}}{2}} \mathrm{k}_{1} \mathrm{v}^{\prime 2} \mathrm{dx}+\frac{1}{2} \int_{\frac{\mathrm{L}}{2}}^{\mathrm{L}} \mathrm{k}_{2} \mathrm{v}^{\prime 2} \mathrm{dx} \\
& \mathrm{U}_{\mathrm{F}}=\frac{1}{2} \mathrm{q}_{\mathrm{v}}{ }^{\mathrm{T}}\left(\mathrm{K}_{\mathrm{F}}+\mathrm{K}_{\mathrm{F}_{1}}+\mathrm{K}_{\mathrm{F}_{2}}\right) \mathrm{q}_{\mathrm{v}}
\end{aligned}
$$

Where $q_{v}$ is vertical DOFs for single lamina beam element. The overall stiffness matrix $\left(\mathrm{K}_{\mathrm{T}}\right)$ may be obtained by combining the beam and foundation stiffness matrices $\left(\mathrm{K}_{\mathrm{b}}, \mathrm{K}_{\mathrm{F}}, \mathrm{K}_{\mathrm{F}_{1}}, \mathrm{~K}_{\mathrm{F}_{2}}\right)$ :

$$
\begin{aligned}
& K_{F}=S_{f}\left[\begin{array}{cccc}
896 & 693 & -252 & 133 \\
& 4536 & -567 & -252 \\
& & 4536 & 693 \\
\text { sym. } & & & 896
\end{array}\right] \\
& K_{F_{1}}=S_{f_{1}}\left[\begin{array}{cccc}
2309 & -2682 & 477 & -104 \\
& 4671 & -2376 & 387 \\
& & 2241 & -342 \\
\text { sym. } & & & 59
\end{array}\right] \\
& K_{F_{2}}=S_{f_{2}}\left[\begin{array}{cccc}
1517 & -4716 & 4761 & -1562 \\
& 15363 & -15498 & 4851 \\
& & 17793 & -7056 \\
\text { sym. } & & & 3767
\end{array}\right] \\
& K_{T}=K_{b}+K_{F}+K_{F_{1}}+K_{F_{2}}
\end{aligned}
$$


where $S_{s}=\frac{G A}{120 L}, S_{b}=\frac{E I}{3 L}, S_{a}=\frac{E A}{3 L}$,

$S_{f_{1}}=\frac{k_{1}}{640 L}, S_{f}=\frac{k_{f} L}{11760} S_{f_{2}}=\frac{k_{2}}{640 L}$.

Mass matrix can be obtained using energy method:

$$
\begin{aligned}
& T=\frac{1}{2} \dot{q}_{v}{ }^{T} \underline{m}_{v} \dot{q}_{v}+\frac{1}{2} \dot{q}_{u}{ }^{T} \underline{m}_{u} \dot{q}_{u} \\
& +\frac{1}{2} \dot{q}_{\phi}{ }^{T} \underline{m}_{\phi} \dot{q}_{\phi}=\frac{1}{2} \dot{q}^{T} \underline{m} \dot{q}
\end{aligned}
$$

Where $\dot{\mathrm{q}}$ and $\underline{\underline{\mathrm{m}}}$ are nodal velocity vector and mass matrix, respectively.

$$
\stackrel{m}{=}=\left[\begin{array}{cccccccccc}
224 C & 0 & 0 & 0 & 112 C & 0 & 0 & -56 C & 0 & 0 \\
& 128 C & 0 & 99 C & 0 & 0 & -36 C & 0 & 19 C & 0 \\
& & 224 R & 0 & 0 & 112 R & 0 & 0 & 0 & -56 R \\
& & & 648 C & 0 & 0 & -81 C & 0 & -36 C & 0 \\
& & & & 896 C & 0 & 0 & 112 C & 0 & 0 \\
& & & & 896 R & 0 & 0 & 0 & 112 R \\
& & & & & 648 C & 0 & 99 C & 0 \\
& & & & & & & 224 C & 0 & 0 \\
& & & & & & & 128 C & 0 \\
& & & & & & & & 224 R
\end{array}\right]
$$

Where $\mathrm{C}=\frac{2 \rho b \mathrm{~L}}{1680}, \mathrm{R}=\frac{2 \rho \mathrm{pt}^{3} \mathrm{~L}}{5040}$ and $L, \rho, 2 t, b$ are length, density, thickness and width of beam element, respectively.

Modeling of laminated beam element: Figure 3 represents a laminated beam element. The first layer in this element has ten DOFs in the axial, vertical and rotational directions, while the other layers have only three rotational DOFs. This is due to the compatibility relationships between the adjacent layers in axial, vertical and rotational displacements. In this case the total number of DOFs for $\mathrm{n}$ layer element will be $(3 n+7)$.

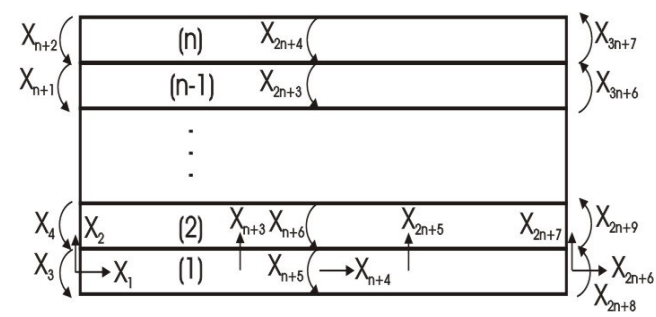

Fig. 3: Modeling of laminated beam element

Let the local displacement vector to be the noted by $\mathrm{u}^{(\mathrm{i})}$ with ten elements namely three axial, four vertical and three rotational displacements. Then the assembled displacement vectors $\mathrm{X}^{(\mathrm{i})}$ for lamina $\mathrm{i}$ will have $10+3(\mathrm{n}-\mathrm{i})$ elements. Let the conversion matrix between $\mathrm{u}^{(\mathrm{i})}$ and $\mathrm{X}^{(\mathrm{i})}$ to be presented by $\mathrm{R}^{(\mathrm{i})}$, then:

$\mathrm{u}^{(\mathrm{n})}=\mathrm{R}^{(\mathrm{n})} \mathrm{X}^{(\mathrm{n})}$

$\mathrm{u}^{(\mathrm{n}-1)}=\mathrm{R}^{(\mathrm{n}-1)} \mathrm{X}^{(\mathrm{n}-1)}$

$\mathrm{u}^{(\mathrm{n}-2)}=\mathrm{R}^{(\mathrm{n}-2)} \mathbf{X}^{(\mathrm{n}-2)}$, etc.
$R^{(i)}$ has dimension $10 \times(10+3 n-3 i)$ and is given by:

All $\mathbf{R}_{\mathrm{j}, \mathrm{k}}{ }^{(\mathrm{i})}=0$ except:

$\left\{\begin{array}{l}R_{j, j}{ }^{(i)}=1 \quad \text { For } j=1,2,3 \\ R_{j, j+n-i}{ }^{(i)}=1 \quad \text { For } j=4,5,6 \\ R_{j, j+2 n-2 i}{ }^{(i)}=1 \quad \text { For } j=7,8,9,10\end{array}\right\}$

Note that the column vectors $\mathrm{X}^{(\mathrm{n})}, \mathrm{X}^{(\mathrm{n}-1)}, \ldots, \mathrm{X}^{(1)}=\mathrm{X}$ have dimensions $(10 \times 1),(13 \times 1), \ldots,((3 n+7) \times 1)$, respectively.

The relationship between the elements of the adjacent layers ( $X^{(i-1)}$ and $X^{(i)}$ ) may be represented by transformation matrices as follows:

$\mathrm{X}^{(\mathrm{n})}=\mathrm{T}^{(\mathrm{n}-1)} \mathrm{X}^{(\mathrm{n}-1)}$

$\mathrm{X}^{(\mathrm{n}-1)}=\mathrm{T}^{(\mathrm{n}-2)} \mathrm{X}^{(\mathrm{n}-2)}$,etc.

All $\mathrm{T}_{\mathrm{j}, \mathrm{k}}^{(\mathrm{i})}=0$ except:

$\mathrm{T}_{1,1}{ }^{(\mathrm{i})}=1, \quad \mathrm{~T}_{1,3}{ }^{(\mathrm{i})}=-\mathrm{t}^{(\mathrm{i})}, \quad \mathrm{T}_{1,4}{ }^{(\mathrm{i})}=-\mathrm{t}^{(\mathrm{i}+1)}$

$\mathrm{T}_{2,2}{ }^{(\mathrm{i})}=1$

$T_{j, j+1}{ }^{(i)}=1 \quad$ For $\quad 3 \leq j \leq 3+n-i$

$\left\{\begin{array}{l}\mathrm{T}_{\mathrm{j}, \mathrm{n}-\mathrm{i}+5}{ }^{(\mathrm{i})}=1, \quad \mathrm{~T}_{\mathrm{j}, \mathrm{n}-\mathrm{i}+6}{ }^{(\mathrm{i})}=-\mathrm{t}^{(\mathrm{i})}, \quad \mathrm{T}_{\mathrm{j}, \mathrm{n}-\mathrm{i}+7}{ }^{(\mathrm{i})}=-\mathrm{t}^{(\mathrm{i}+1)} \\ \text { For } \mathrm{j}=4+\mathrm{n}-\mathrm{i}\end{array}\right\}$

$T_{j, j+2}^{(i)}=1 \quad$ For $\quad n-i+5 \leq j \leq 5+2(n-i)$

$\left\{\begin{array}{l}\mathrm{T}_{\mathrm{j}, 2(\mathrm{n}-\mathrm{i})+8}{ }^{(\mathrm{i})}=1, \quad \mathrm{~T}_{\mathrm{j}, 2(\mathrm{n}-\mathrm{i})+10^{(i)}}=-\mathrm{t}^{(\mathrm{i})}, \quad \mathrm{T}_{\mathrm{j}, 2(\mathrm{n}-\mathrm{i})+11}{ }^{(\mathrm{i})}=-\mathrm{t}^{(\mathrm{i}+1)} \\ \text { For } \mathrm{j}=2(\mathrm{n}-\mathrm{i})+6\end{array}\right\}$

$T_{j, j+2}{ }^{(i)}=1 \quad$ For $\quad j=7+2(n-i)$

$T_{j, j+3}{ }^{(i)}=1 \quad$ For $\quad 2(n-i)+8 \leq j \leq 3(n-i)+7$

Note that $\mathrm{T}^{(\mathrm{i})}$ has dimension $(7+3 n-3 i) \times(10+3 n-3 i) . \mathrm{t}^{(\mathrm{i})}$ is the half thickness of lamina i. Applying the local to global transformation matrices, the assumed global stiffness and mass matrices can be calculated as follows:

$[K]=\left(R^{1}\right)^{T} k^{1} R^{1}+\left(T^{1}\right)^{T}\left(R^{2}\right)^{T} k^{2} R^{2} T^{1}+\left(T^{1}\right)^{T}\left(T^{2}\right)^{T}\left(R^{3}\right)^{T} k^{3} R^{3} T^{2} T^{1}(14)$

$+\ldots+\left(T^{1}\right)^{T}\left(T^{2}\right)^{T} \ldots\left(T^{n-1}\right)^{T}\left(R^{n}\right)^{T} k^{n} R^{n} T^{n-1} \ldots T^{2} T^{1}$

$[M]=\left(R^{1}\right)^{T} m^{1} R^{1}+\left(T^{1}\right)^{T}\left(R^{2}\right)^{T} m^{2} R^{2} T^{1}+\left(T^{1}\right)^{T}\left(T^{2}\right)^{T}\left(R^{3}\right)^{T} m^{3} R^{3} T^{2} T^{1}(15)$

$+\ldots+\left(T^{1}\right)^{T}\left(T^{2}\right)^{T} \ldots\left(T^{n-1}\right)^{T}\left(R^{n}\right)^{T} m^{n} R^{n} T^{n-1} \ldots T^{2} T^{1}$

Where $\mathrm{k}^{(\mathrm{i})}$ and $\mathrm{m}^{(\mathrm{i})}$ are the local stiffness and mass matrices of lamina $i$ with dimension $(10 \times 10)$.

Single-stepped beam modeling: Stepped beam have numerous applications in industry. Modeling of these beams has been always a challenge for engineers, especially at the stepped location where a sudden transition takes places in the physics of the problem.

Figure 4 illustrates a stepped beam comprised of two lengthwise elements of $j^{\text {th }}$ and $(j-1)^{\text {th }}$. Let number of adjacent laminas at stepped location to be $\mathrm{n}_{\mathrm{j}}$ and $\mathrm{n}_{\mathrm{j}-1}$. At this location $\mathrm{X}_{1}, \mathrm{X}_{2}$ displacements of 
element (j) may be related to displacement of element (j-1) by transformation matrix $\Pi^{\mathrm{j}}$.

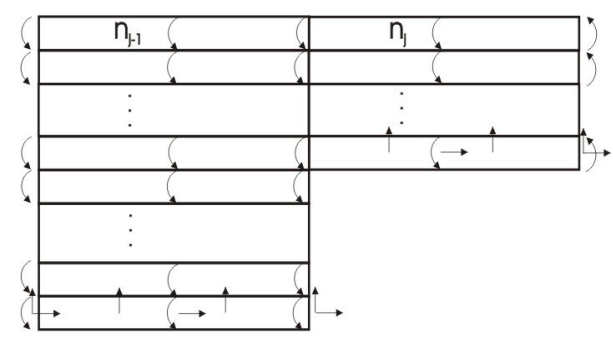

Elem.(j-1)

Elem.(j)

Fig. 4: Adjacent elements of single-stepped beam

We define a vector $\mathrm{X}^{j^{\prime}}$ as the stepped location displacement vector. The modified form of DOFs is obtained as following:

$\mathrm{X}^{(\mathrm{j})}=\Pi^{(\mathrm{j})} \mathrm{X}^{\left(\mathrm{j}^{\prime}\right)}$

Transformation matrix $\Pi^{\mathrm{j}}$ has dimension $\left(3 n_{j}+7\right) \times\left(2 n_{j}+n_{j-1}+7\right)$, where it is given by the following relations:

All $\Pi_{j, k}^{(i)}=0$ except:

$\Pi_{1,1}{ }^{j}=1, \quad \Pi_{1,3}{ }^{j}=-t^{(1)}, \quad \Pi_{1, n_{j-1}-n_{j}+3}{ }^{j}=-t^{\left(n_{j-1}-n_{j}+1\right)}$

$\Pi_{1, \mathrm{i}+2}{ }^{\mathrm{j}}=-2 \mathrm{t}^{(\mathrm{i})} \quad$ For $\quad 2 \leq \mathrm{i} \leq \mathrm{n}_{\mathrm{j}-1}-\mathrm{n}_{\mathrm{j}}$

$\Pi_{2,2}{ }^{j}=1$

$\Pi_{i},,_{n_{j-1}-n_{j}+i}{ }^{j}=1$ For $\quad i \geq 3$

The changed stiffness matrix $\mathrm{K}^{\mathrm{j}^{\prime}}$ at stepped location also can be written as:

$\mathrm{K}^{\mathrm{j}^{\prime}}=\left(\Pi^{\mathrm{j}}\right)^{\mathrm{T}} \mathrm{K}^{\mathrm{j}} \Pi^{\mathrm{j}}$

$\mathrm{K}^{\mathrm{j}^{\prime}}$ can be used in the assembling of the global stiffness matrix. In a similar manner, the changed mass matrix may be written as:

$\mathbf{M}^{\mathrm{j}^{\prime}}=\left(\Pi^{\mathrm{j}}\right)^{\mathrm{T}} \mathbf{M}^{\mathrm{j}} \Pi^{\mathrm{j}}$

Equations of motion: The free vibration equation of motion for a laminated beam can be written as:

$[\mathrm{M}]\{\ddot{\mathrm{X}}\}+[\mathrm{K}]\{\mathrm{X}\}=\{0\}$

Where $[\mathrm{k}]$ and $[\mathrm{M}]$ are global stiffness and mass matrices. Considering the general solution of the system $X=X_{0} \mathrm{e}^{\mathrm{i} \omega \mathrm{t}}$, we obtain:

$\left[\mathrm{K}-\omega^{2} \mathrm{M}\right] \mathrm{X}_{0}=0$

By solving the eigenvalue problem (Eq.21), the natural frequencies of the system can be obtained.

\section{RESULTS AND DISCUSSION}

To the best of our knowledge, up to now no reference could be found analyzing the free vibration of single-stepped LCB on Paternak foundation. Hence, to validate the result of our analysis, at this stage we can only compare the result of our free vibration analysis of cross-ply LCB without Pasternak foundation with other existing results and then continue our analysis for a LCB on a Pasternak foundation. Furthermore, we will present the numerical results of a stepped LCB on Pasternak foundation.

Unless mentioned otherwise, beam material has been considered AS4/3501 Graphite/Epoxy with the following mechanical and physicals properties ${ }^{[9]}$ :

$\mathrm{E}_{11}=144.8 \mathrm{GPa}, \quad \mathrm{E}_{22}=9.65 \mathrm{GPa}, \quad \mathrm{G}_{12}=4.14 \mathrm{GPa}$, $\mathrm{G}_{13}=4.14 \mathrm{GPa}, \mathrm{G}_{23}=3.45 \mathrm{GPa}$

$\mathrm{V}_{12}=0.3, \mathrm{p}=1389.23 \mathrm{~kg} / \mathrm{m}^{3}, \mathrm{~L} / \mathrm{h}=15, \mathrm{~b}=0.15 \mathrm{~m}$

The shear correction factor is assumed to be $5 / 6$. For all cases the natural frequencies are presented using the non-dimensional form $\bar{\omega}=\omega L^{2} \sqrt{\rho / E_{11} h^{2}}$.

The non-dimensionalized first three natural frequencies of a symmetric cross-ply [0/90/90/0] for clamped-clamped(C-C), clamped-supported(C-S) and clamped-free(C-F) boundary conditions are compared in Table 1 with the similar results presented in ${ }^{[5-7]}$. The latter character in E1 and E2 indicate the number of element ${ }^{[7]}$. As it can be seen from this table, good agreement exists between the obtained results in this work and other references.

In Table 2, the first three non-dimensional fundamental frequencies of non-symmetric cross-ply LCBs are presented for C-C boundary condition.

As shown in Table 1 and 2, Natural frequencies of the beam decrease for non-symmetric arrangement [0/90/0/90] with respect to symmetric arrangement $[0 / 90 / 90 / 0]$ of the laminas. For the beam boundary conditions as (C-F), (C-S) and (C-C), the natural frequencies of LCBs increase from low to high values, respectively which is the case for an isotropic single layer continuous beam.

Timoshenko ${ }^{[10]}$ has investigated vibration of single layer isotropic beam on an elastic foundation (Winkler $\mathrm{k}_{1}=\mathrm{k}_{2}=0$ ) on the basis of Euler-Bernoulli beam theory. He found the frequencies to be as follow:

$\omega_{\mathrm{i}}=\mathrm{k}_{\mathrm{i}}^{2} \mathrm{a} \sqrt{1+\mathrm{k}_{\mathrm{f}} /\left(\mathrm{EIk}_{\mathrm{i}}^{4}\right)}$

Where $a^{2}=E I /(\rho A)$ and $\left(k_{i} L\right)^{2}$ ought to be calculated based on the boundary conditions. Results of this work for single lamina beam are compared with that Timoshenko in Table 3 with the following numerical properties:

$E=200 \mathrm{GPa} \quad, G=77 \mathrm{GPa} \quad, \rho=7000 \mathrm{~kg} / \mathrm{m}^{3} \quad, b=0.3 \mathrm{~m}$
$t=0.1 \mathrm{~m} \quad, L=6 \mathrm{~m} \quad, k_{f}=150 \mathrm{kN} / \mathrm{m}^{2}$

As it can be seen that the Euler-Bernoulli beam theory predict more natural frequencies than the Timoshenko beam theory as expected. The maximum error is related to the case of $\mathrm{C}-\mathrm{C}$ on the third mode, which is about $2 \%$. 
Table 1: Comparison of non-dimensionalised natural frequencies of symmetric cross-ply beams[0/90/0/90]

\begin{tabular}{|c|c|c|c|c|c|c|}
\hline Beam type & Mode No. & [6] & [7] & E1[8] & E2[8] & Pre. \\
\hline \multirow[t]{3}{*}{$\mathrm{C}-\mathrm{C}$} & 1 & 4.618 & 4.594 & 4.643 & 4.644 & 4.617 \\
\hline & 2 & 10.796 & 10.291 & 10.927 & 10.928 & 10.471 \\
\hline & 3 & 16.984 & 16.966 & 17.541 & 17.545 & 18.160 \\
\hline \multirow[t]{3}{*}{ C-S } & 1 & 3.613 & 3.525 & - & - & 3.706 \\
\hline & 2 & 9.569 & 9.442 & - & - & 9.650 \\
\hline & 3 & 16.482 & 16.384 & - & - & 17.384 \\
\hline \multirow[t]{3}{*}{ C-F } & 1 & - & 0.924 & 0.923 & 0.922 & 0.923 \\
\hline & 2 & - & 4.892 & 4.921 & 4.921 & 4.920 \\
\hline & 3 & - & 11.440 & 11.596 & 11.596 & 11.585 \\
\hline
\end{tabular}

Table 2: Comparison of non-dimensionalised natural frequencies of non-symmetric cross-ply beams [0/90/0/90]

\begin{tabular}{llrr}
\hline & Mode No. & {$[6]$} & Pre. \\
\hline C-C & 1 & 3.736 & 3.732 \\
& 2 & 9.187 & 9.181 \\
& 3 & 15.102 & 15.097 \\
\hline
\end{tabular}

Table 3: Comparison of single layer beam on elastic foundation

\begin{tabular}{llrr}
\hline & Mode No. & {$[10]$} & Pre. \\
\hline C-F & 1 & 1.199 & 1.197 \\
& 2 & 6.383 & 6.360 \\
& 3 & 17.823 & 17.814 \\
C-C & 1 & 6.497 & 6.474 \\
& 2 & 17.823 & 17.894 \\
& 3 & 34.936 & 34.238 \\
C-S & 1 & 4.491 & 4.488 \\
& 2 & 14.448 & 14.306 \\
& 3 & 30.029 & 29.657 \\
S-S & 1 & 2.919 & 2.917 \\
& 2 & 11.420 & 11.473 \\
& 3 & 25.671 & 25.378 \\
\hline
\end{tabular}

Table 4: Non-dimensionalised frequencies of symmetric and nonsymmetrical uniform LCB on uniform Pasternak foundation

\begin{tabular}{llll}
\hline & Mode No. & {$[0 / 90 / 0 / 90]$} & {$[0 / 90 / 90 / 0]$} \\
\hline C-F & 1 & 1.042 & 1.267 \\
& 2 & 4.525 & 5.692 \\
& 3 & 10.582 & 12.979 \\
$\mathrm{C}-\mathrm{C}$ & 1 & 3.752 & 4.714 \\
& 2 & 8.832 & 10.632 \\
& 3 & 15.918 & 18.346 \\
$\mathrm{C}-\mathrm{S}$ & 1 & 2.973 & 3.819 \\
& 2 & 7.938 & 9.811 \\
& 3 & 14.849 & 17.578 \\
\hline
\end{tabular}

As it was mentioned before, until now no solution was found in the existing literatures for the free vibrations of LCB types of beams. Hence, four different configuration of beam-foundation are analyzed. This combination are: LCB with uniform cross-section on uniform and stepped Pasternak foundation, LCB with stepped cross-section on stepped Pasternak foundation and multi-span LCB with uniform cross-section on uniform Pasternak foundation. Foundation parameters are considered to be as follows:

$k_{f}=100 \mathrm{kN} / \mathrm{m}^{3}, k_{1}=200 \mathrm{kN}, k_{2}=150 \mathrm{kN}$

Results of the analysis for all cases considered are presented in Table 4-7.

Case (1): Results of uniform LCBs on uniform Pasternak foundation.
Case (2): Results of the analysis of uniform LCBs on stepped Pasternak foundation with $\mu$ as ratio of foundation length to beam length (Fig. 5)

Case (3): Results of the natural frequencies of stepped LCBs on stepped Pasternak foundation (Fig. 6). As indicated in Table 5 and 6 by increasing the length of the foundation, frequencies of LCB increase.

Case (4): Results of multi-span beam with m span and beam length L (Fig. 7).

In this case foundation parameters are: $k_{f}=100 \mathrm{kN} / \mathrm{m}^{3}, k_{1}=k_{2}=150 \mathrm{kN}$

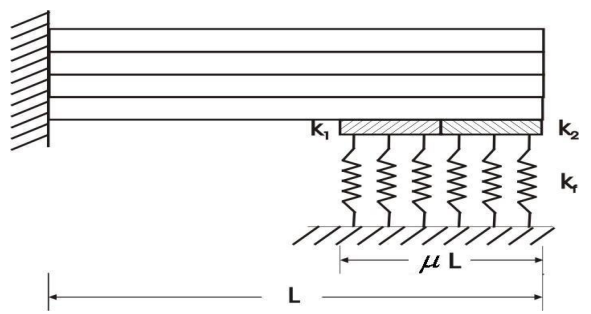

Fig. 5: Uniform LCB on stepped Pasternak foundation

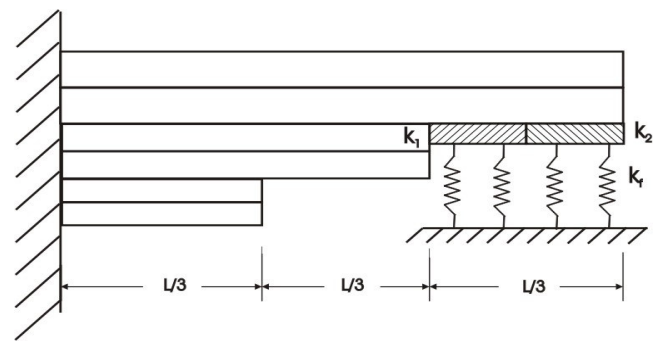

Fig. 6: Stepped LCB on stepped Pasternak foundation

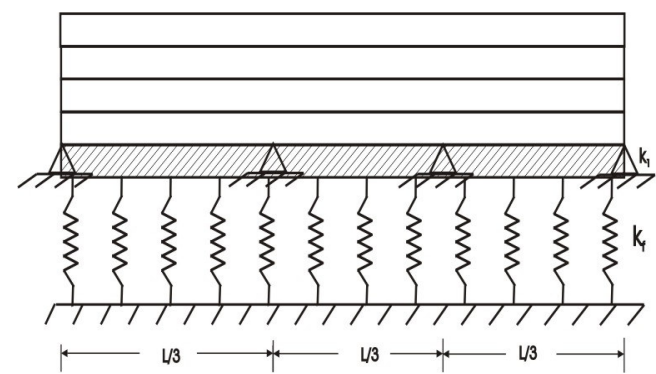

Fig. 7: Three span LCB with uniform cross-section on uniform Pasternak foundation 
Table 5: Non-dimensionalised frequencies of symmetric and nonsymmetrical LCB on stepped Pasternak foundation

\begin{tabular}{llcc}
\hline$\mu$ & Mode No. & {$[0 / 90 / 0 / 90]$} & {$[0 / 90 / 90 / 0]$} \\
\hline $1 / 3$ & 1 & 0.926 & 1.175 \\
& 2 & 4.424 & 5.612 \\
& 3 & 10.414 & 12.847 \\
$2 / 3$ & 1 & 1.017 & 1.248 \\
& 2 & 4.471 & 5.649 \\
& 3 & 10.525 & 12.932 \\
& 1 & 1.042 & 1.267 \\
& 2 & 4.525 & 5.692 \\
& 3 & 10.582 & 12.979 \\
\hline
\end{tabular}

Table 6: Non-dimensionalised frequencies of symmetric and nonsymmetric stepped LCBs on stepped Pasternak foundation

\begin{tabular}{llll}
\hline$\mu$ & Mode No. & {$[0 / 90 / 0 / 0 / 90 / 0]$} & {$[0 / 90 / 0 / 90 / 0 / 0]$} \\
\hline $1 / 3$ & 1 & 1.895 & 1.977 \\
& 2 & 4.695 & 5.746 \\
& 3 & 9.253 & 10.744 \\
$2 / 3$ & 1 & 1.966 & 2.052 \\
& 2 & 4.707 & 5.761 \\
& 3 & 9.362 & 10.844 \\
& 1 & 1.981 & 2.066 \\
& 2 & 4.729 & 5.795 \\
& 3 & 9.409 & 10.884 \\
\hline
\end{tabular}

Table 7: Non-dimensionalised frequencies of multi-span LCB on uniform Pasternak foundation

\begin{tabular}{llcc}
\hline $\mathrm{m}$ & Mode No. & {$[0 / 90 / 90 / 0]$} & {$[0 / 90 / 0 / 90]$} \\
\hline 1 & 1 & 3.224 & 2.458 \\
& 2 & 8.624 & 6.770 \\
& 3 & 16.987 & 13.977 \\
2 & 1 & 9.952 & 7.894 \\
& 2 & 23.485 & 19.658 \\
& 3 & 40.002 & 35.901 \\
& 1 & 14.164 & 12.834 \\
& 2 & 41.012 & 36.683 \\
& 3 & 63.031 & 58.758 \\
\hline
\end{tabular}

It should be noted that increasing the span number will not increase the length and weight of the beam. It is clear that as number of spans for a beam increases the natural frequencies also increases. Also, obtained results indicate that as the orientation of the laminas change from symmetric to non-symmetric arrangements, the natural frequencies decrease.

\section{CONCLUSION}

In this study, free vibration analysis of a cross-ply LCB on Pasternak foundation is investigated. For the first time to-date, the same analysis was conducted for a single-stepped LCB on Paternak foundation. Comparison of the findings for simple cases with the results reported in the literature indicates acceptable accuracy and good agreement. In a similar manner, as isotropic single layer continuous beam natural frequencies for LCB with boundary conditions (C-F), (C-S) and (C-C) increases from lower values to higher values, respectively. Results indicate as laminas deviated from symmetric to non-symmetric order the natural frequencies decreased.

\section{REFERENCES}

1. Patel, B.P., M. Ganapathi and M. Touratier, 1999. Nonlinear free flexural vibrations /post-buckling analysis of laminated orthotropic beams/columns on a two parameter elastic foundation. Composite Structures, 46: 189-196.

2. Thambiratnam, D. and Y. Zhuge, 1996. Free vibration analysis of beams on elastic foundation. Computers \& Structures, 60: 971-980.

3. Banerjee, J.R., 1998. Free vibration of axially loaded composite timoshenko beams using the dynamic stiffness matrix method. Computers \& Structures, 69: 197-208.

4. Yuan, F.G. and R.E. Miller, 1989. A new finite element for laminated composite beams. Computers \& Structures, 31: 737-745.

5. Krishnaswamy, S., K. Chandrashekhara and W.Z.B. Wu, 1992. Analytical solutions to vibration of generally layered composite beams. J. Sound and Vibration, 159: 85-99.

6. Chandrashekhara, K., K. Krishnamurthy and S. Roy, 1990. Free vibration of composite beams including rotary inertia and shear deformation. Composite Structures, 14: 269-279.

7. Subramanian, P., 2006. Dynamic analysis of laminated composite beams using higher order theories and finite elements. Composite Structures, 73: 342-353.

8. Zienkiewicz, O.C., 1997. The Finite Element Method. McGraw-Hill, London.

9. Jones, R.M., 1975. Mechanics of Composite Materials. New York: Mc Graw-Hill.

10. Timoshenko, S.P., D.H. Young and W. Weaver, 1974. Vibration Problems in Engineering. John Wiley and Sons, New York. 